\title{
Learning to be a Prison Educator
}

\author{
by NICOLE PATRIE \\ NorQuest College
}

\begin{abstract}
For many correctional educators, the learning curve upon beginning to teach in prisons can be steep. This paper explores issues that are encountered by correctional educators: culture shock, skill or knowledge gaps, and philosophical dilemmas. With experience as a correctional educator and administrator, the author presents a training and mentorship program developed as a result of correctional education expansion in Alberta, Canada. Formalizing the training and mentorship program has proven to be a successful structure under which correctional educators can be supported through all phases of their development.
\end{abstract}

Keywords: correctional education; prison education; instructor training; professional development

\section{Introduction}

Learning to teach in non-traditional environments such as correctional institutions differs greatly from learning to teach in traditional education. The field of correctional education straddles justice and education systems; systems that are often in conflict over philosophy, policy, and practice. As such, those new to correctional education must learn to navigate the system with which they are unfamiliar (justice), and work within it to accomplish goals and outcomes put forward by the education system. For many correctional educators this can involve overcoming the initial culture shock of institutional life as well as addressing personal knowledge and skill gaps in areas such as alternative education, security, and law. Some correctional educators may experience philosophical dilemmas as a result of getting to know their environment and students.

Considering that these challenges are quite different from challenges in traditional education, it is important to tailor the training of correctional educators to be corrections-specific. As part of their training, those who are new to secure environments should be introduced to issues prior to being confronted by them. The actual extent to which correctional educators encounter issues will vary according to the institution in which they work, as well as their individual teaching experience, personality, and teaching assignment. Once correctional educators have acclimated to correctional education, ongoing professional development is equally important; correctional educators need to have access to both formal and informal venues in which they can explore the intricacies of correctional education as issues arise.

\section{Context for Developing a Training and Mentorship Program}

In 2013, our Correctional Education Department expanded to offer programs at a new remand facility that had been built ${ }^{1}$. As a result of the new centre, correctional educators were hired, most of whom were beginning their teaching careers and had little experience in corrections and/or education ${ }^{2}$. Orienting groups of new correctional educators at the same time necessitated formalizing a training and mentorship program for future educators. The department has since begun to look at ongoing staff development and to seek out the best ways to support correctional educators as they encounter challenges and develop their identities as correctional educators. This paper provides a discussion of issues that can be encountered by correctional educators, as well as a brief overview of the training and mentorship program that was found to work best for the facility. Providing appropriate training and orientation to new correctional educators, as well as opportunities for meaningful ongoing development has been important to ensure that educators are adequately supported in their development. 


\section{Issues Encountered by Correctional Educators}

Those involved in correctional education will inevitably encounter difficulties and challenges unique to prison settings. Research into correctional education tends to focus on three types of issues: Culture Shock, Skill and Knowledge Gaps, and Existential and Philosophical Crises (DelliCarpini, 2008; Jurich, Casper \& Hull, 2001; Whitehead, 2013; Wright, 2008; Yanz, 2008). Although there is a dearth of research into how correctional educators move through and between these three categories, anecdotally correctional educators tend to first encounter them in the order they are presented below. Existential and philosophical issues tend to arise once correctional educators feel comfortable with the daily happenings in their classrooms and begin trying to reconcile their worldviews and philosophies of human nature with their correctional experiences.

\section{Culture Shock}

\section{"I never really knew what prison or prisoners were like"}

Society usually encounters prisons only through news reports and sensationalized entertainment, which can lead to many assumptions about institutions. Prisoners, officers, and prisons are neither similar to how many imagine them to be nor how they are portrayed in the media. Assumptions held by new correctional educators are challenged as they experience the real institutional environment (Wright, 2008). Similarly, a newcomer to corrections will also be confronted with their pre-conceived assumptions about a variety of social issues (addictions, poverty, culture/race, etc) as well as their beliefs regarding what students, education, and school should look like. Correctional education often has little resemblance to traditional education.

Furthermore, correctional institutions each have their own specific culture. As a result of being places where people live all aspects of their lives closed off from society, institutions also breed unique subcultures (Goffman, 1961). Both officers and prisoners have their own subcultures with unwritten standards of behaviour, and other groups (educators, psychologists, chaplains, etc) who work within institutions often have their own unique subcultures. Educators must learn to work within and between these cultures. Often the dominant officer and prisoner cultures within an institution are incongruent with education and contradict the worldviews of educators. As such, these contradictions can become a source of stress for the correctional educator.

While all adult students come to education with a wealth of experience and personal knowledge, students in corrections also come with additional issues and crises that preclude education (Wright \& Gehring, 2008). For example, students in prison must deal with relationship problems, family deaths, divorce, immigration, and child custody as a result of their incarceration. Institutional problems such as intimidation, gambling, drugs, and gang issues can also impact students' ability to fully participate in education (Wright \& Gehring, 2008). Issues relating to both their lives outside and inside the institution make it even more difficult for students in correctional institutions to learn than adult learners in the outside community.

As a result, educators in correctional institutions are often expected to be more than educators; they must be teachers, counselors, and security agents (Jurich et al., 2001). Learning to take on and work between these multiple identities is another manifestation of culture shock that many correctional educators experience. Security concerns take precedence over education and the correctional educator is limited to use only security-approved materials and activities. Without an abundance of resources, the challenge becomes how to "make learning so interesting, so worthwhile, so enjoyable that the students elect to stay and learn because it is exciting, interesting, fun, and incredibly valuable" (Jurich et al., 2001).

\section{Skills or Knowledge Gaps}

\section{"I need new skills to help me teach such a diverse group in such a different place"}

Although classes in correctional education are typically small, students in corrections are a diverse group. Correctional educators encounter issues related to students' discontinuous education experiences, learning disabilities, and mental health issues. As a result of institutional restrictions on class size and student movement, it might not be possible to assign students to classrooms based on education level; therefore, many classrooms are heterogeneous. It is equally uncommon in Canada that educators come to correctional education already having experience with alternative or adult education ${ }^{3}$. Without previous training, correctional educators may struggle to address students' needs (DelliCarpini, 2008). 
Jurich et al. (2001) conducted a needs assessment of 373 correctional educators to identify a number of workshops they would be interested in attending. Of the top ten requested workshops, eight were related to skill or knowledge development. Requested workshops included: learning styles, basic criminology, safety, classroom management, and communication skills. While launching the new education program it was found that once correctional educators became more at ease in the institution they tended to encounter skill or knowledge gaps similar to those identified by Jurich et al. (2001), including:

\section{Communication Skills}

- Problem solving

- De-escalating

- Non-verbal communication

\section{Understanding Human Behaviour}

- Addictions

- Psychology/Psychopathology

- Sociology and criminology

\section{Specialized Instructional Techniques}

- Teaching within the limits of a prison classroom

- Learning disabilities

- Heterogeneous classrooms

- Differentiated group instruction

Depending on the specific teaching-assignment and classroom dynamics, correctional educators may find that they require some additional skills, knowledge, or teaching instructional techniques in order to be fully effective in their classrooms. Since most educators came to the program with experience in traditional education, most of their needs centred on how to adapt their current instructional styles to adult students in a prison environment.

\section{Existential/Philosophical Issues}

"I am not simply an adult educator - prison changes everything. It changes me"

Many correctional educators encounter a variety of philosophical dilemmas while learning to teach and teaching in correctional institutions. These dilemmas can include: negotiating the conflicting philosophies of education and corrections, developing empathy for students who have allegedly committed horrible crimes, assisting prisoners as they develop new identities as students, and coming to terms with the impact that prisons have on everyone involved (including themselves). Dichotomies of good/bad, black/white, right/wrong, and innocent/guilty are challenged daily.

In theory, justice and education systems share common goals: education, rehabilitation, and successful re-entry. In practice, however, the two systems can have irreconcilable differences. Correctional institutions are focused on security, control, and power, and often use a behaviour modification model. Foucault (1977) noted that the prison "is supposed to apply the law, and to teach respect for it; but all its functioning operates in the form of an abuse of power" (p. 266). In contrast, adult education returns power to the student. It aligns with cognitive and social learning models, focusing on personal and societal improvement, self-direction, and a belief that all people have capacity and desire for learning. Often correctional education struggles to fit between these two philosophies with correctional educators attempting to create an atmosphere of adult education inside the correctional institution. In so doing correctional education is controversial and political by nature. Whitehead (2013) explained that since corrections and education have different purposes, goals, and outcomes, there is more potential for correctional educators to encounter ethical dilemmas. The primary obligation of everyone in corrections is security, which can conflict with a correctional educator's "obligations to the student, the education department, or fellow correctional educators" (Whitehead, 2013). In spite of a correctional educator's desire to support all students, they often can find themselves in the difficult position of 
ending a student's participation in education because that student violated prison rules.

Wright and Gehring (2008) discussed how correctional educators set up classrooms as places of value, respect, worth, and choice. These places, or "spheres of civility," foster an environment of adult education and personal development (Wright \& Gehring, 2008). However, they can be a source of internal conflict for students as they transition daily between identities of student and prisoner. Spheres of civility can also become a place of internal conflict for correctional educators when students behave one way in class and return to living units to behave in a completely opposite manner (possibly sabotaging their participation in class and challenging the correctional educator's view of them).

Similar to the students' identity conflicts, correctional educators can find themselves labeled as outsiders: segregated from adult education in the community but also segregated from other prison practices (Yantz, 2008). In this isolation, Yantz (2008) struggled with her identity as a professional, being overlooked in both education and corrections, and with understanding the role she played in both spheres. This begs the question of whether or not it is possible to work in a correctional environment without being affected by it. As correctional educators become settled with their teaching assignments and students, they may begin working through such philosophical questions.

\section{Training and Mentorship Program}

The previously mentioned training and mentorship program developed by the Correctional Education Department consists of three phases: initial formal training, initial informal training, and ongoing informal training. New correctional educators have a variety of backgrounds, with experience and certification as either secondary-level professional teachers, or social workers, psychologists or community workers ${ }^{2,3}$.

Upon receiving security clearance to the institution new correctional educators will undergo initial formal training. They must participate in formal security orientation from Correctional Staff. Correctional educators will learn security practices specific to the institution, chain of command, examples of contraband items, and placement information. An institution tour will highlight areas in the institution with which correctional educators need to be familiar (i.e., offices, classrooms). If possible correctional educators will be shown an empty classroom so that they can see the environment in which they will be working. The final part of formal training is the staff training manual. At this stage, correctional educators are also shown the location of any curriculum material they might need and given some time to digest and become familiar with their surroundings and class materials.

Ideally, educators who are new to correctional education will have two to three weeks before they begin teaching their own classes. During this time they will take part in informal training through classroom observations and team-teaching with more experienced correctional educators. They will observe the intricacies of prison education, develop relationships with other educators, and gather a variety of strategies for use in their classrooms.

An important part of this informal training is debriefing with other correctional educators or staff. Correctional educators should have time to reflect on their practice, sharing with others and making sense of their experiences. When pairing new correctional educators for team-teaching or classroom observations it is important to note which experienced correctional educators will be able to provide opportunity for reflection and debriefing. If an environment of group sharing and disclosure can be encouraged from the outset they will be more likely to remain engaged with their peers in supporting each other on an ongoing basis. Debriefing experiences with other experienced correctional educators can help new educators process the culture shock, skill or knowledge gaps, and philosophical issues described above.

As correctional educators transition from merely observing individual classes or sessions to team teaching entire courses and ultimately to managing their own classroom, they progress into ongoing informal training. This phase transitions into regular continuous professional development for all correctional educators. When a new correctional educator is teaching their first class they might need more additional support and conversation than when they are months or years in the position. However, it is important that ongoing dialogue is always available.

Throughout training, the focus is on creating and maintaining an environment where correctional ed- 
ucators can discuss, reflect on, and solve issues that arise as they become more comfortable with their position as a correctional educator. Correctional educators often feel a sense of isolation that can be ameliorated through peer collaboration. Peer collaboration can also protect against complacency that can develop as correctional educators begin to adapt to the correctional environment (Ropp, 2008).

\section{Ongoing Professional Development}

Of course, educators adjust to the correctional environment differently and will choose to engage with the issues described above in various capacities and quantities. Since the correctional education environment differs greatly from traditional education, ongoing professional development should focus on the challenges of teaching in corrections (Jurich et al, 2001). It is crucial to have opportunities, formal and informal, to debrief and to engage in reflective practice. DelliCarpini (2008) noted the importance of providing opportunities to "pose questions specific to their context, focus on content and pedagogical skills, and form collaborative partnerships within their own facility and with teachers in other facilities". It is common for each institution to have few correctional educators in each subject area, isolated from others doing similar work in different institutions. Therefore, the need to develop a community of practice is perhaps more important in a prison setting than in other educational settings.

Communities of practice are defined as a group of people with a common interest, who form a group together, and who have a practice related to the interest (Lave \& Wenger, 1991). As the group interacts they learn more about the topic, share personal knowledge and experiences, and experiment with alternative methods. In corrections, a community of practice is one way that educators can support each other through culture shock, share teaching strategies and skills specific to a restrictive environment, and discuss existential issues. Being consistently involved in a community of practice is one way to address the loneliness inherent in correctional education.

One example of a community of practice is simply taking time to debrief with other correctional educators or education staff working in the same institution. Another would be connecting with correctional educators from different institutions and maintaining communication throughout the year (through an online community, face to face meetings, etc). Being involved in a community of practice is one way to continually support a new correctional educator as they move out of the initial training phase. For seasoned correctional educators, a community of practice can protect against complacency and jadedness. Communities of practice can provide a place for correctional educators to provide each other with support, trouble shooting, brainstorming, and reflection (DelliCarpini, 2008).

In addition to participating in a community of practice, correctional educators should also have opportunities for formal professional development (such as workshops, courses, additional study, and conferences). DelliCarpini (2008) noted that professional development is most effective when the focus is on three areas: student learning, subject matter knowledge, and alignment with the actual conditions of the classroom. Since both the student population and the classroom conditions in correctional education differ greatly from those involved in traditional education, it is important to have development opportunities specifically designed for the correctional educator. These opportunities are offered through correctional education associations and department-organized training opportunities.

\section{Conclusion}

Through the training and mentorship program outlined above, a new educator is allowed time to observe the prison environment, view classes and team-teach. This provides a structure through which initial culture shock, skills gaps, and philosophical issues can be discussed before the new educator is more isolated in their own classroom. The program also helps integrate the new educator into a community of practice where debriefing experiences with others is welcome. Both new and experienced correctional educators should have access to colleagues with whom they can debrief and process daily experiences, as well as meaningful and relevant professional development opportunities. Outlining the importance of ongoing development through a training and mentorship program has enabled the department to highlight development opportunities as a necessity. Together the group can develop effective practices, experiment with new initiatives, address issues, and safeguard against security concerns. 
Correctional Education is full of contrasts: uniforms / jumpsuits, speaking to / speaking with, strict hierarchy / spheres of civility, and emphasis on total control / student autonomy. Often people involved in correctional education find themselves caught in the middle of these contrasts. Correctional educators have a way of speaking with students, and advocate for maximizing class-time and participation. The most obvious example of these contrasts is how educators refer to people in class: students, not inmates or prisoners. As a result of being seen as "doubly outside" (not exactly regular education and not exactly regular prison administration), correctional educators can occasionally walk a fine line of welcome in their institutions. Appropriate initial and ongoing training opportunities, formal and informal, can provide support to correctional educators in the unique positions they hold in their institutions.

\section{Footnotes}

1. The facility is currently the largest in Alberta (Canada), capable of housing up to 1600 people remanded until trial. While the remand centre was designed with the intention of offering programming, classrooms are decentralized and located on each living unit. The institution houses both males and females, in both medium and maximum security areas. Correctional educators work in most areas of the institution.

2. Correctional education programs in Alberta are delivered through local community colleges. Educators are faculty members of the college and work under the terms of the faculty association's collective agreement. There is no specialized training in adult education or correctional education upon being hired. Workshops in adult education practices are available through the college; however, these rarely coincide with date-of-hire. Correctional educators have at minimum bachelor's degree in education, social work, psychology, or a related field. Some educators possess a teaching certificate from the Ministry of Education; those who teach secondary-level academic courses must have a temporary teaching certificate and are eligible to earn their permanent teaching certificate while working at the college.

3. In Canada, undergraduate teacher-training programs focus on either primary or secondary education. There are few graduate programs in adult education, none of which culminate in a teaching certificate. As a result, correctional educators teaching secondary-level academic courses have experience and certification in secondary education. Those teaching non-academic courses might have experience in social work, psychology, or community work.

\section{References}

DelliCarpini, M. (2008). Creating communities of professional practice in the correctional education classroom. Journal of Correctional Education, 59(3), 219-230.

Foucault, M. (1977). Discipline and punish: The Birth of the prison. New York: Vintage Books.

Goffman, E. (1961). Asylums: Essays on the social situation of mental patients and other inmates. Chicago: Aldine Publishing Company.

Jurich, S., Casper, M., \& Hull, K.A. (2001). Training correctional educators: A needs assessment study. Journal of Correctional Education, 52(1).

Lave, J., \& Wenger, E. (1991). Situated Learning: Legitimate Peripheral Participation. Cambridge: Cambridge University Press.

Ropp, P. (2008). Crossing borders: The problem of professional boundaries. In R. Wright (Ed.), In the borderlands: Learning to teach in prisons and alternative settings. San Bernardino: California State University.

Whitehead, C.L. (2013). Ethics in correctional education. In M.S. Plakhotnik \& S.M. Nielsen (Eds.), Proceedings of the $12^{\text {th }}$ Annual South Florida Education Research Conference (p. 226-232). Miami: Florida International University. Retrieved November 15, 2016 from: http://education.fiu.edu/research_conference/ docs/proceedings/SFERC $\% 202013$ \%20Proceedings $\% 20$ of $\% 20$ the $\% 2012$ th $\% 20$ Annual $\% 20$ South $\% 20$ Florida\%20Educatio.pdf

Wright, R. (2008). In the borderlands: Learning to teach in prison and alternative settings. San Bernardino: 
California State University.

Wright, R. \& Gehring, T. (2008). From spheres of civility to critical public spheres: Democracy and citizenship in the big house (Part 1). Journal of Correctional Education, 59(3), 244-260.

Yantz, S. (2008). Borderlands negotiation: Re-presentation of identity as a prison educator. In R. Wright (Ed.), In the borderlands: Learning to teach in prison and alternative settings (pp. 147-158). San Bernardino: California State University.

Author comments: An earlier version of this paper was presentented in 2015 at the following conference: "Innovative Strategies in Criminal Justice: From Policy to Practice." The conference was sponsored by the John Howard Society of Alberta. The presentation was titled "Between two worlds: Training educators to provide programs in correctional settings."

Nicole Patrie is the Associate Chair of Correctional Education at NorQuest College. She has an MEd in Education Policy Studies (Adult Education) from the University of Alberta. 